\title{
Load Frequency Control in Deregulated Power System by Grey- Wolf Optimization Algorithm
}

\author{
A. Yuva Kishore ${ }^{1 *}$, P. V. Naresh Babu ${ }^{2}$, J. Chinnaraj $^{3}$ and E. Murali Raghava ${ }^{4}$ \\ $1^{*}$ Assistant professor, Department of Electrical and Electronics Engineering, \\ Annamacharya Instittute of Technology and Sciences, Tirupathi \\ ${ }^{2,3}$ Graduate student, Department of Electrical and Electronics Engineering, \\ YITS, Tirupathi \\ ${ }^{4}$ Industrial trainer, Department of Electrical and Electronics Engineering, \\ Sree Vidyanikethan Engineering college, Tirupathi \\ I*a.yuvakishor@gmail.com, ${ }^{2}$ nareshnaren222@gmail.com, \\ ${ }^{3}$ chinnaraj509h@gmail.com, ${ }^{4}$ emuraliraghava@gmail.com
}

\begin{abstract}
Load frequency control (LFC) is one of the key issues in the operation of power systems under deregulated conditions. In this paper Grey-Wolf Optimization (GWO) algorithm is implemented in optimal tuning of Proportional, Integral and Derivative (PID) controller with Integral Time Absolute Error (ITAE) based fitness function. The performance of this system is tested under different market conditions like Poolco, Bilateral and contract violation scenarios. Here we consider Distribution company (DISCO) Participation Matrix (DPM) and Area Participation Matrix (APM) in order to incorporate the market dynamics. Also Generation Rate Constraints $(G R C)$ and external load disturbances are also taken into account. The analysis and simulations is carried out in inter-connected two-area deregulated power system and the effectiveness is compared with Genetic Algorithm (GA) tuned PID controller. The comparative results are presented which shows the superiority of proposed GWO algorithm.
\end{abstract}

Keywords: Load Frequency control, Area control error, Poolco model, bilateral transaction, fitness function, Meta-heuristic optimization, Grey-Wolf algorithm

\section{Introduction}

Load frequency control problem mainly arises due to intermittent load demand variations causing power imbalances between generation and demand. It is considered as one of prominent ancillary services in deregulated power system [1]. The main objectives of LFC problem are to minimize the frequency deviations from nominal frequency and to maintain the scheduled tie-line oscillations [2]. In conventional or Vertically Integrated Units(VIU), the whole operations of generation, transmission and distribution were under control of single utility. Due to deregulation unbundling happened and given rise to separate entities like generation companies (GENCO), Transmission companies (TRANSCO), Distribution companies (DISCOM) and Independent system operators(ISO). The role of GENCO and TRANSCO are very important in maintaining the scheduled power values, limiting the frequency deviations and control power exchange variations.

Extensive literature surveys over load frequency control under deregulated environment have been presented by A. Pappachen [3]. This method includes intelligent control techniques like Fuzzy gain [4], Artificial neural networks using reinforced

Received (March 5, 2018), Review Result (May 17, 2018), Accepted (May 23, 2018)

* Corresponding Author 
learning (ANN) [5], Adaptive-Neuro Fuzzy controller [6]. The optimization control techniques include Genetic algorithm (GA) [7], Bacterial Foraging optimization technique (BFO) [8], Particle Swarm Optimization (PSO) [9], Optimal Firefly algorithm [10], Harmony Search algorithm [11] and others.

Some control theory techniques were also implemented for load frequency control like Robust control technique by H-infinity approach [12], Sliding Mode Control [13], Model Predictive Control [14]. Only some of these methods only considered bilateral transactions and they do not consider some effects like Generation Rate Constraints (GRC) and load reference set point limitation.

In this paper GWO algorithm is implemented for LFC problem under deregulated conditions considering GRC and load reference set point limitations. GWO algorithm is used for tuning of gain values in PID controller. The proposed method is verified on Twoarea power system with different contact scenarios.

\section{Two-area Power System Under Study}

In this section power system model under study is described i.e., a two-area power system [7] and its schematic diagram is represented in Figure 1.

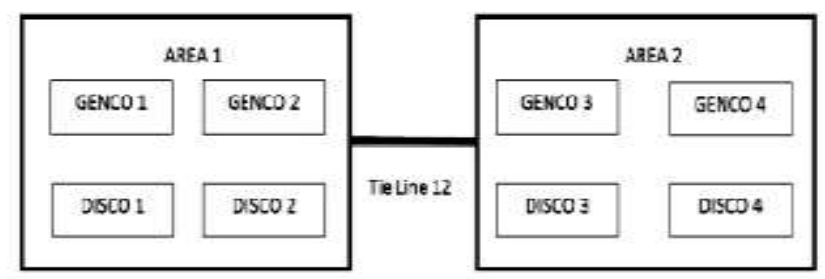

Figure 1. Schematic Block Diagram of Two-Area Power System

It consists of two control areas and each control area is connected through a tie-line. As it is deregulated environment each control area consists of combination of GENCO and DISCO. GENCOs sells power to various DISCOs with competitive prices [15]. Each control area consists of Two GENCOs and Two TRANSCOs. For this power system, implementation of LFC is represented in Figure 2.

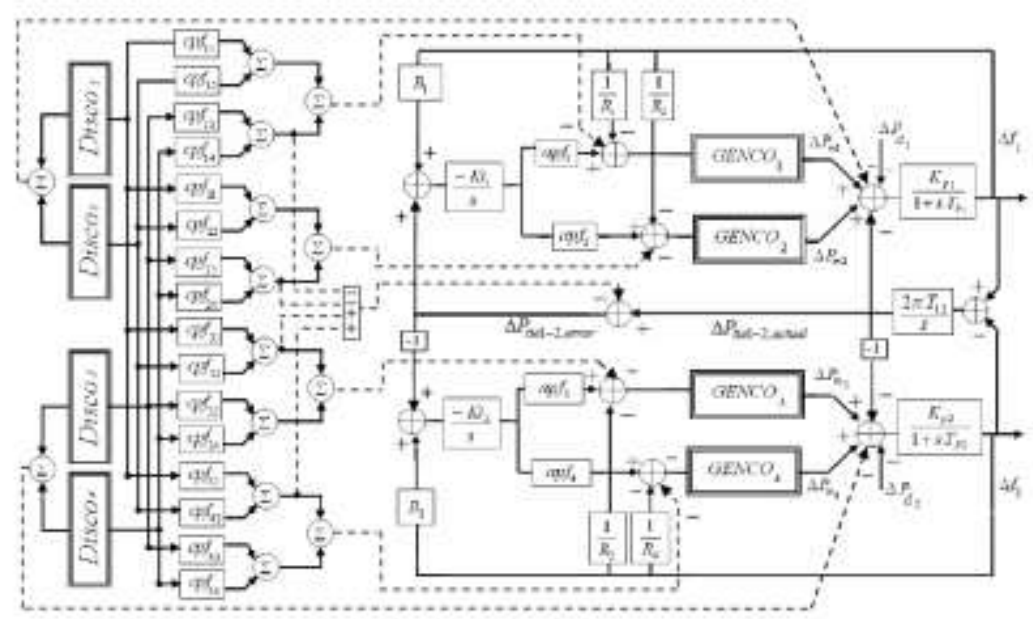

Figure 2. Block Diagram of Two-Area Power System for LFC Implementation

\subsection{DISCO Participation Matrix (DPM):}

DPM is used for perception of contracts in the restructured power system. It is a matrix with an order of number of GENCOs by number of DISCOs i.e., number of rows is equal 
to number of GENCOs and number of columns is equal to number of DISCOs [1]. Each entry in the matrix the 'Contract Participation Factor (cpf)' of that corresponding row and column. Contract Participation Factor is the ratio of the power contracted by a particular DISCO from a particular GENCO to the total power contracted by that DISCO. DPM for this two-area power system is given in equation (1).

$$
\mathrm{DPM}=\left[\begin{array}{llll}
\mathrm{cpf}_{11} & \mathrm{cpf}_{12} & \mathrm{cpf}_{13} & \mathrm{cpf}_{14} \\
\mathrm{cpf}_{21} & \mathrm{cpf}_{22} & \mathrm{cpf}_{23} & \mathrm{cpf}_{24} \\
\mathrm{cpf}_{31} & \mathrm{cpf}_{32} & \mathrm{cpf}_{33} & \mathrm{cpf}_{34} \\
\mathrm{cpf}_{41} & \mathrm{cpf}_{42} & \mathrm{cpf}_{43} & \mathrm{cpf}_{44}
\end{array}\right]
$$

Where $\quad \mathrm{cpf}_{\mathrm{ij}}=$ Fraction of total load power contracted by $\mathrm{j}^{\text {th }}$ DISCO from $\mathrm{i}^{\text {th }}$ GENCO

From DPM, the entries corresponding to $\mathrm{jth}$ DISCO i.e., total entries in $\mathrm{j}^{\text {th }}$ column results in equation (2).

$$
\sum_{\mathrm{i}=1}^{\mathrm{n}} \mathrm{cpf}_{\mathrm{ij}}=1, \forall \mathrm{j}=1,2, \ldots \ldots ., \mathrm{m}
$$

Where $\mathrm{n}=$ number of GENCOs

$\mathrm{m}=$ number of DISCOs

\subsection{Area Participation Matrix (APM):}

DISCOs cannot stick to the conditions in the contract of power allocation from GENCOs for all the times, it may violates the rule at some times and hence the uncontracted power demand rises. These uncontracted power demands are allocated by GENCOs to the DISCOs in the same area. While developing the dynamic model, this allocation of uncontracted power demands is also very important. APM is used for this allocation based on 'Area Participation Factor (apf)' [16]. APM is in order with number of rows is equal to number of GENCOs in the considered area and number of columns is equal to number of areas.. APM for $\mathrm{p}^{\text {th }}$ control area is given in equation (3)

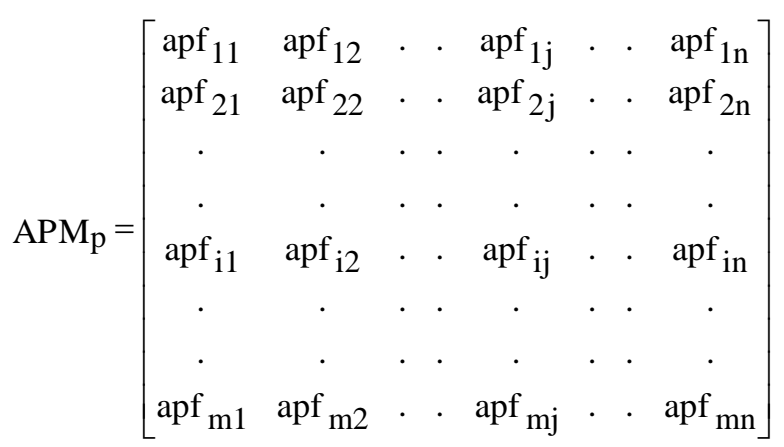

Where $a f_{i j}=$ Participation factor of $\mathrm{i}^{\text {th }}$ GENCO in $\mathrm{p}^{\text {th }}$ area to meet the $\mathrm{j}^{\text {th }}$ demand area

$$
\begin{aligned}
& \mathrm{m}=\text { number of GENCOs in } \mathrm{p}^{\text {th }} \text { area } \\
& \mathrm{n}=\text { number of areas }
\end{aligned}
$$

As both DPM and APM are considered, the change in output power from each GENCO are calculated in equation (4). 


$$
\left[\begin{array}{c}
\Delta \mathrm{P}_{1}^{\mathrm{E}} \\
\Delta \mathrm{P}_{2}^{\mathrm{E}} \\
\Delta \mathrm{P}_{3}^{\mathrm{E}} \\
\Delta \mathrm{P}_{4}^{\mathrm{E}}
\end{array}\right]=\mathrm{DPM}\left[\begin{array}{l}
\Delta \mathrm{P}_{1}^{\mathrm{C}} \\
\Delta \mathrm{P}_{2}^{\mathrm{C}} \\
\Delta \mathrm{P}_{3}^{\mathrm{C}} \\
\Delta \mathrm{P}_{4}^{\mathrm{C}}
\end{array}\right]+\mathrm{APM}\left[\begin{array}{l}
\Delta \mathrm{P}_{1}^{\mathrm{U}} \\
\Delta \mathrm{P}_{2}^{\mathrm{U}}
\end{array}\right]
$$

Where $\Delta \mathrm{P}_{\mathrm{i}}^{\mathrm{E}}=$ Change in Power output in $\mathrm{i}^{\text {th }}$ GENCO

$$
\begin{aligned}
& \Delta \mathrm{P}_{\mathrm{j}}^{\mathrm{C}}=\text { Contracted load demand from } \mathrm{j}^{\text {th }} \text { DISCO } \\
& \Delta \mathrm{P}_{\mathrm{P}}^{\mathrm{U}}=\text { Uncontracted load demand in } \mathrm{p}^{\text {th }} \text { control area }
\end{aligned}
$$

In this case, corresponding APM is given in equation (5)

$$
\mathrm{APM}=\left[\begin{array}{cc}
\operatorname{apf}_{1} & 0 \\
\operatorname{apf}_{2} & 0 \\
0 & \operatorname{apf}_{3} \\
0 & \operatorname{apf}_{4}
\end{array}\right]
$$

\subsection{Problem Formulation:}

The scheduled power flow during steady state in the tie-line is given as

$$
\begin{gathered}
\Delta P_{12, s c h}^{\mathrm{E}}=\text { (Demand in DISCOs in Area1 to GENCOs in Area2) - (Demand in DISCOs in } \\
\text { Area1 to GENCOs in Area2) }
\end{gathered}
$$

But the actual power flow would be

$$
\Delta \mathrm{P}_{12, \text { act }}^{\mathrm{E}}=\frac{2 \pi \mathrm{T}_{12}}{\mathrm{~s}}\left(\Delta \mathrm{F}_{1}-\Delta \mathrm{F}_{2}\right)
$$

In the same we can define $\Delta \mathrm{P}_{21 \text {,sch }}^{\mathrm{E}}$ and $\Delta \mathrm{P}_{21 \text {,act }}^{\mathrm{E}}$.

Based on the above equations we define the error in the tie-line can be calculated as,

$$
\Delta \mathrm{P}_{12, \text { error }}^{\mathrm{E}}=\Delta \mathrm{P}_{12, \text { act }}^{\mathrm{E}}-\Delta \mathrm{P}_{12, \text { sch }}^{\mathrm{E}}
$$

This error becomes zero in steady state when the actual power flow equals to scheduled power flow in the tie line. Based on this error, 'Area Control Error (ACE)' for each area are defined as

$$
\begin{aligned}
& \mathrm{ACE}_{1}=\mathrm{B}_{1} \Delta \mathrm{F}_{1}+\Delta \mathrm{P}_{12 \text {,error }}^{\mathrm{E}} \\
& \mathrm{ACE}_{2}=\mathrm{B}_{2} \Delta \mathrm{F}_{2}+\Delta \mathrm{P}_{21 \text {,error }}^{\mathrm{E}}
\end{aligned}
$$

Where $\mathrm{B}_{1}, \mathrm{~B}_{2}$ are frequency bias factors

$\Delta \mathrm{F}_{1}, \Delta \mathrm{F}_{2}$ are steady state frequency deviation functions.

Objective function:

The Objective function is to be defined initially for designing a controller by considering the constraints and required specifications. In optimal controller design objective function is selected based on i) response of the system within few seconds and ii) response of system for complete time i.e., Integral criterion. The different performance indices based on integral criteria are Integral Square Error (ISE), Integral Absolute Error (IAE), Integral Time multiples of Squared Error (ITSE) and Integral of Time-weighted 
Absolute Error (ITAE). Since ITAE gives better performance when compared to others [10], we define ITAE as objective function or fitness function given below.

$$
\mathrm{J}=\int_{0}^{\mathrm{t}_{\text {sim }}}\left(\left|\Delta \mathrm{F}_{1}\right|+\left|\Delta \mathrm{F}_{2}\right|+\mid \Delta \mathrm{P}_{\text {error }}^{\mathrm{E}}\right) * \mathrm{tdt}
$$

Where $\mathrm{t}_{\mathrm{sim}}=$ total simulation time

\section{Grey-wolf Optimization Algorithm}

This algorithm was developed based on leadership hierarchy and hunting mechanism of Grey Wolves [17]. They also known as Timber wolves. As per their hunting qualities they are classified as four categories namely $\operatorname{Alpha}(\alpha), \operatorname{Beta}(\beta), \operatorname{Delta}(\delta)$ and $\operatorname{Omega}(\Omega)$.

Alpha category wolves are at the top of the hierarchy which are leaders of the pack and they decide hunting, sleeping place, wake-up time etc., They may be male or female and not mandatory to be stronger among the all. This category wolves are followed by Beta category which in the next level or second level of hierarchy. The lowest level in the hierarchy is occupied by Omega wolves. They just follow the instructions of higher order wolves. The remaining wolves which are not under any one of above categories are Delta category and these are responsible for siting boundaries, security alerts, care taking of injured wolves etc. The main steps of gray wolf hunting are as follows [17]:

(i) Tracking, chasing and approaching the prey.

(ii) Pursuing, encircling and harassing the prey until it stop moving.

(iii) Attack towards the prey.

\subsection{Mathematical Modeling of GWO:}

Some important terminology and concepts are provided below before going for mathematical modeling of GWO.

\section{Social hierarchy :}

In this hierarchy Alpha wolves are considered as best fit solutions and are followed by Beta, Delta and finally Omega.

\section{Encircling:}

The encircling behavior of wolves around the prey is given by [17], is provided in following

$$
\begin{aligned}
& \vec{D}=\left|\vec{D} \cdot \overrightarrow{X_{p}}(t)-\vec{X}(t)\right| \\
& \vec{x}(t+1)=\overrightarrow{x_{p}}(t)-\vec{A} \cdot \vec{D}
\end{aligned}
$$

Where $\overrightarrow{x p}(t)$ denotes the current position of victim and the coefficient vectors $\overrightarrow{\mathrm{A}}$, $\overrightarrow{\mathrm{C}}$ are calculated as below.

$$
\begin{aligned}
& \overrightarrow{\mathrm{A}}=2 \cdot \overrightarrow{\mathrm{a}} \overrightarrow{\mathrm{r}_{1}}-\overrightarrow{\mathrm{a}} \\
& \overrightarrow{\mathrm{C}}=2 \cdot \overrightarrow{r_{2}}
\end{aligned}
$$


Where $\overrightarrow{r_{1}}, \overrightarrow{r_{2}}$ are random vectors

\section{Hunting:}

This hunting is instructed by alpha category and also supported by Beta and Delta category wolves. To find the optimum positions, three best solutions(obtained so far)in terms of alpha, beta and delta are saved and remaining solutions including omega are competed. Following formulae are used to update the wolf positions around the prey [17].

$$
\begin{aligned}
& \overrightarrow{\mathrm{D}}_{\alpha}=\left|\overrightarrow{\mathrm{C}}_{1} \overrightarrow{\mathrm{X}}_{\alpha}-\overrightarrow{\mathrm{X}}\right| \\
& \overrightarrow{\mathrm{D}} \beta=\left|\overrightarrow{\mathrm{C}}_{2} \overrightarrow{\mathrm{X}}_{\beta}-\overrightarrow{\mathrm{x}}\right| \\
& \overrightarrow{\mathrm{D}_{\delta}}=\left|\overrightarrow{\mathrm{C}_{3} \mathrm{X}_{\delta}}-\overrightarrow{\mathrm{X}}\right| \\
& \overrightarrow{\mathrm{x}}_{1}=\overrightarrow{\mathrm{x}}_{\alpha}-\overrightarrow{\mathrm{A}}_{1}\left(\overrightarrow{\mathrm{D}}_{\alpha}\right) \\
& \overrightarrow{\mathrm{X}}_{2}=\overrightarrow{\mathrm{X}}_{\beta}-\overrightarrow{\mathrm{A}}_{2}\left(\overrightarrow{\mathrm{D}}_{\beta}\right) \\
& \overrightarrow{\mathrm{x}}_{3}=\overrightarrow{\mathrm{x}}_{\delta}-\overrightarrow{\mathrm{A}}_{3}\left(\overrightarrow{\mathrm{D}}_{\delta}\right) \\
& \overrightarrow{\mathrm{x}}(\mathrm{t}+1)=\frac{\overrightarrow{\mathrm{x}_{1}}+\overrightarrow{\mathrm{x}}_{2}+\overrightarrow{\mathrm{x}}_{3}}{3}
\end{aligned}
$$

\section{Attacking prey(exploitation):}

Two parameters are essential to determine modeling that how the wolves approach the prey. They are $\vec{A}$, decreases linearly from 2 to 0 . The other is $\vec{a}$, which is at random manner also $\vec{A}$ ranges randomly in $[-a, a]$. If $\vec{A}$ ranges in $[-1,1]$, the next position of search agent will be between prey and current positions.

\section{Search for prey:}

The positions of alpha, beta and delta gives the optimum search for GWO. The wolves during search they diverges and during attack they converges. If the values of $\vec{A}$ is more than 1 and less than -1 , it indicates the divergence. One more variable is $\vec{C}$ the value ranges $[0,2]$ which shows impact on defining the distance as per (15). Hence GWO shows more random behavior in entire optimization and enforces the exploration and avoid the local optima.

\subsection{Implementation of GWO for LFC}

In this paper two area network is considered, the objective function is given in (11), this objective function. This objective function ' $\mathrm{J}$ ' has to be minimized subjected to the following constraints. 


$$
\begin{aligned}
\mathrm{K}_{\mathrm{p}(\min )} & \leq \mathrm{K}_{\mathrm{p}} \leq \mathrm{K}_{\mathrm{p}(\max )} \\
\mathrm{K}_{\mathrm{i}(\min )} & \leq \mathrm{K}_{\mathrm{i}} \leq \mathrm{K}_{\mathrm{i}(\max )} \\
\mathrm{K}_{\mathrm{d}(\min )} & \leq \mathrm{K}_{\mathrm{d}} \leq \mathrm{K}_{\mathrm{d}(\max )}
\end{aligned}
$$

Where $\mathrm{Kp}_{\mathrm{p}}, \mathrm{K}_{\mathrm{i}}$ and $\mathrm{K}_{\mathrm{d}}$ are the gains of Proportional, Integral and Derivative controllers.

The step by step algorithm has been described below.

Input parameters of GWO algorithm like search agents, population size ,

Step 1: number of control variables are initialized as per controller variables, upper and lower boundaries, total number of generations and number of elitism parameters.

Step 2: The search agents i.e., Gray wolves $\left(\mathrm{K}_{\mathrm{p}}, \mathrm{K}_{\mathrm{i}}\right.$ and $\left.\mathrm{K}_{\mathrm{d}}\right)$ are initialized to a random values within the upper and lower boundaries of search space.

Step 3: Fitness function is evaluated for (11) and alpha, beta and delta wolves are assigned in the search space.

Step 4: Update the positions of alpha, beta and delta.

Step 5: $\mathrm{r} 1, \mathrm{r} 2$ are two random numbers which are to be assigned between $[0,1]$ and assign a for random and decreasing linearly from 2 to 0 .

Step 6: Update the position of search agents using (16)-(21) and adjust the control variables $\left(\mathrm{K}_{\mathrm{p}}, \mathrm{K}_{\mathrm{i}}\right.$ and $\left.\mathrm{K}_{\mathrm{d}}\right)$ using (23).

Step 7: Check for search agent whether it is within search space or not, the infeasible solutions are to be replaced by randomly generated feasible solution set.

Step 8: Sort the positions of search agents obtained in step 6 from the best value to worst value and use for next generation.

Step 9: Check for termination condition, if fails go to step 4.

\section{Results and Discussions}

In this section, response of two-area power system under deregulated environment with different conditions like Poolco, Bilateral and Contract violation scenarios are observed. The simulation of two-area power system is developed on MATLAB.

\subsection{Poolco based Scenario:}

In this case, the load demand of DISCOs in a particular area is completely observed by the GENCOs in that area. The corresponding DPM and APM are given below in (26) and (27) respectively, indicates contracted power transaction between GENCOs and DISCOMS.

$$
\begin{aligned}
\mathrm{DPM} & =\left[\begin{array}{cccc}
0.5 & 0.5 & 0 & 0 \\
0.5 & 0.5 & 0 & 0 \\
0 & 0 & 1.0 & 1.0 \\
0 & 0 & 0 & 0
\end{array}\right] \\
\mathrm{APM} & =\left[\begin{array}{cc}
0.5 & 0 \\
0.5 & 0 \\
0 & 0.5 \\
0 & 0.5
\end{array}\right]
\end{aligned}
$$


In each $1 \%$ of step load disturbance is created and response is observed shown in following Figure 3, Figure 4 and Figure 5.

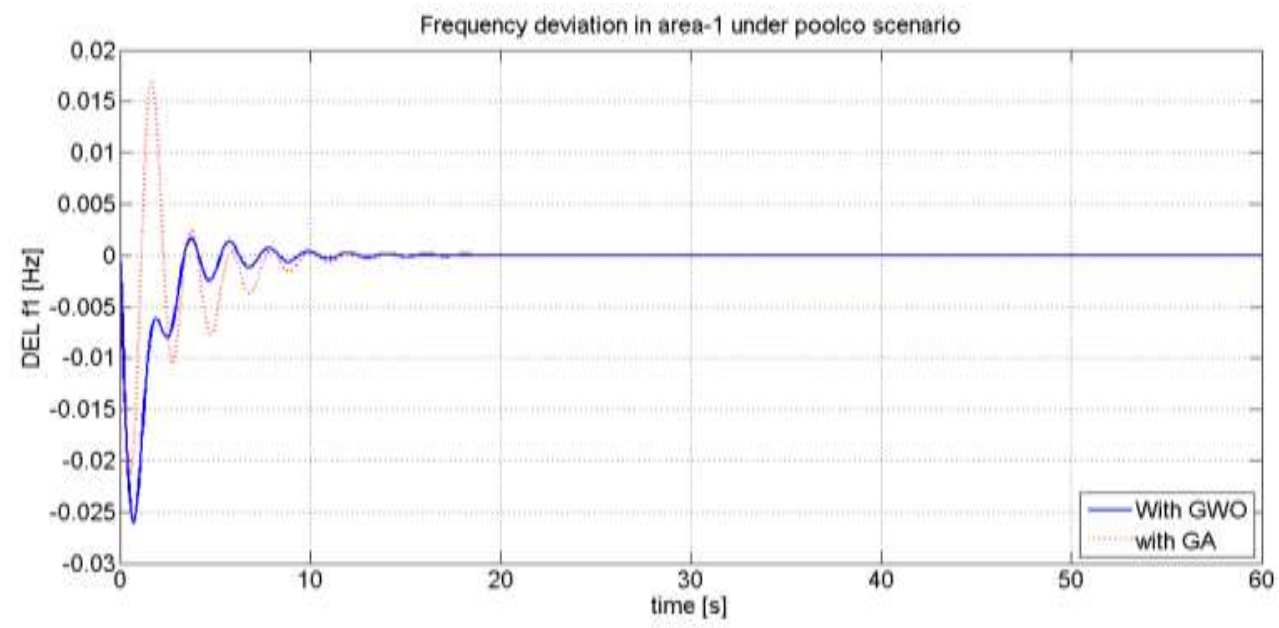

Figure 3. Frequency Deviation in Area-1 under Poolco Scenario

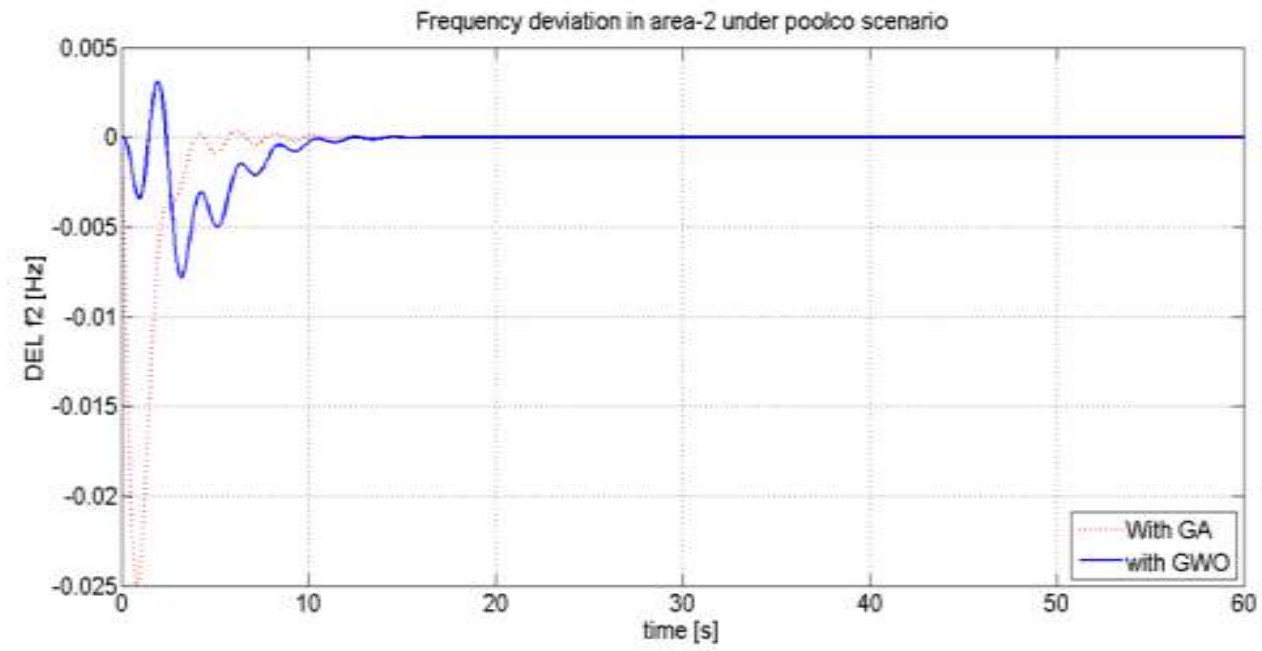

Figure 4. Frequency Deviation in Area-2 under Poolco Scenario

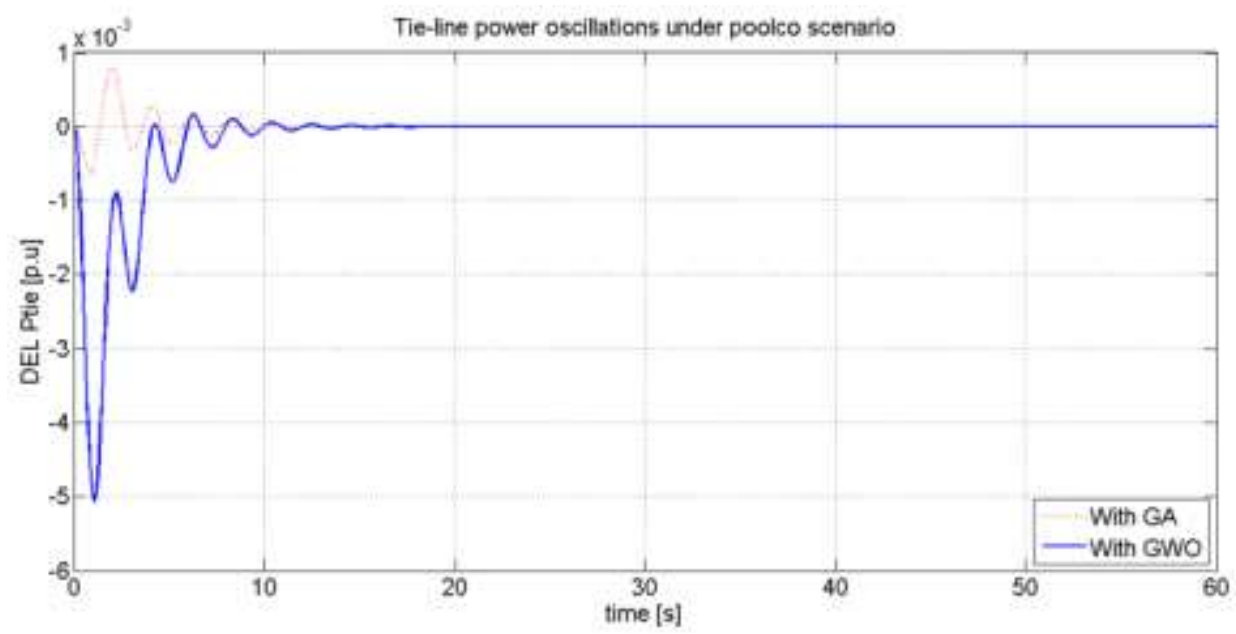

Figure 5. Tie-line Oscillations under Poolco Scenario 
Now the performance evaluation is determined by ITAE, settling time and peak overshoot. In Table 1, the comparison of ITAE error for GA tuned and GWO tuned PID controller is presented.

\section{Table 1. Comparison of ITAE, Settling Time and Peak Overshoot Under Poolco Scenario}

\begin{tabular}{|c|c|c|c|}
\hline \multicolumn{2}{|c|}{ Performance Index } & $\boldsymbol{G A}$ & $G W O$ \\
\hline \multicolumn{2}{|c|}{ ITAE } & 2.775 & 2.542 \\
\hline \multirow{3}{*}{$\begin{array}{l}\text { Settling time } \\
\text { (Ts in sec) }\end{array}$} & $\Delta \mathrm{f}_{1}$ & 9.66 & 9.52 \\
\hline & $\Delta \mathrm{f}_{2}$ & 9.25 & 9.16 \\
\hline & $\Delta \mathrm{P}_{\text {tie }}$ & 8.66 & 9.51 \\
\hline \multirow{3}{*}{ Peak overshoot } & $\Delta \mathrm{f}_{1}$ & 0.025 & 0.022 \\
\hline & $\Delta \mathrm{f}_{2}$ & 0.026 & 0.012 \\
\hline & $\Delta \mathrm{P}_{\text {tie }}$ & 0.0018 & 0.005 \\
\hline
\end{tabular}

\subsection{Bilateral Scenario:}

In this case DISCOs have freedom to trade the power from any GENCO belonging to any area whereas in Poolco condition DISCO have to trade power from GENCO of their own area only. Now the corresponding DPM, APM are shown below (28), (29).

$$
\begin{aligned}
\mathrm{DPM} & =\left[\begin{array}{cccc}
0.25 & 0.3 & 0.4 & 0.25 \\
0.25 & 0.2 & 0.1 & 0.25 \\
0.3 & 0.25 & 0.25 & 0.3 \\
0.2 & 0.25 & 0.25 & 0.2
\end{array}\right] \\
\mathrm{APM} & =\left[\begin{array}{cc}
0.3 & 0.25 \\
0.2 & 0.25 \\
0.25 & 0.4 \\
0.25 & 0.1
\end{array}\right]
\end{aligned}
$$

The dynamic response of two-area power system under bilateral scenario is shown in Figure 6, Figure 7 and Figure 8.

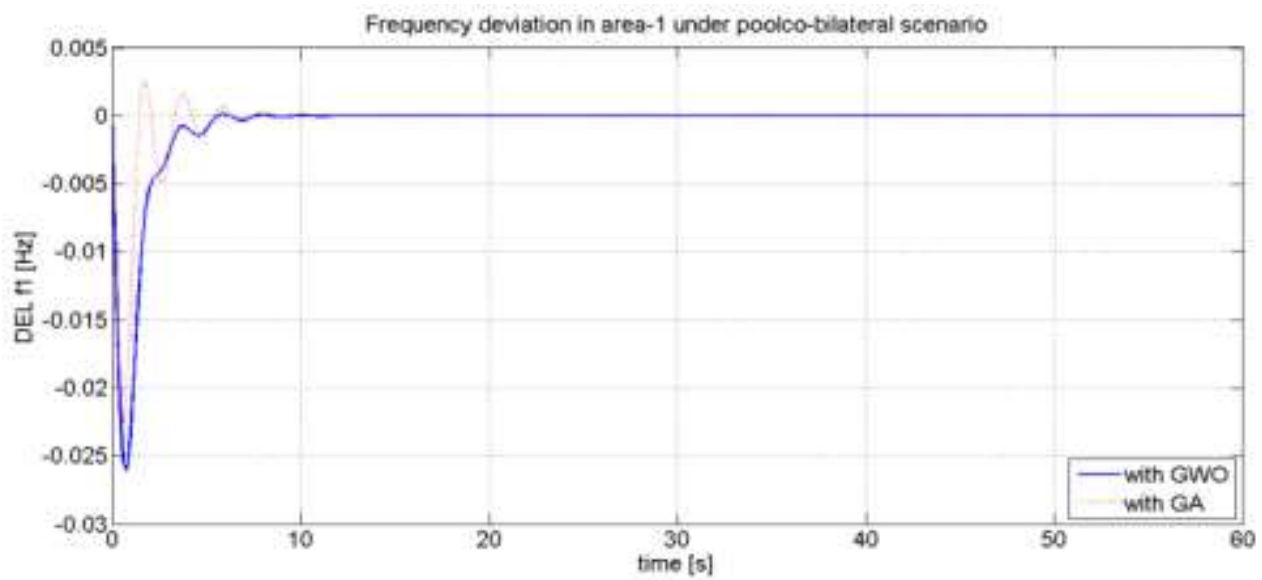

Figure 6. Frequency Deviation in area-1 under Bilateral Scenario 


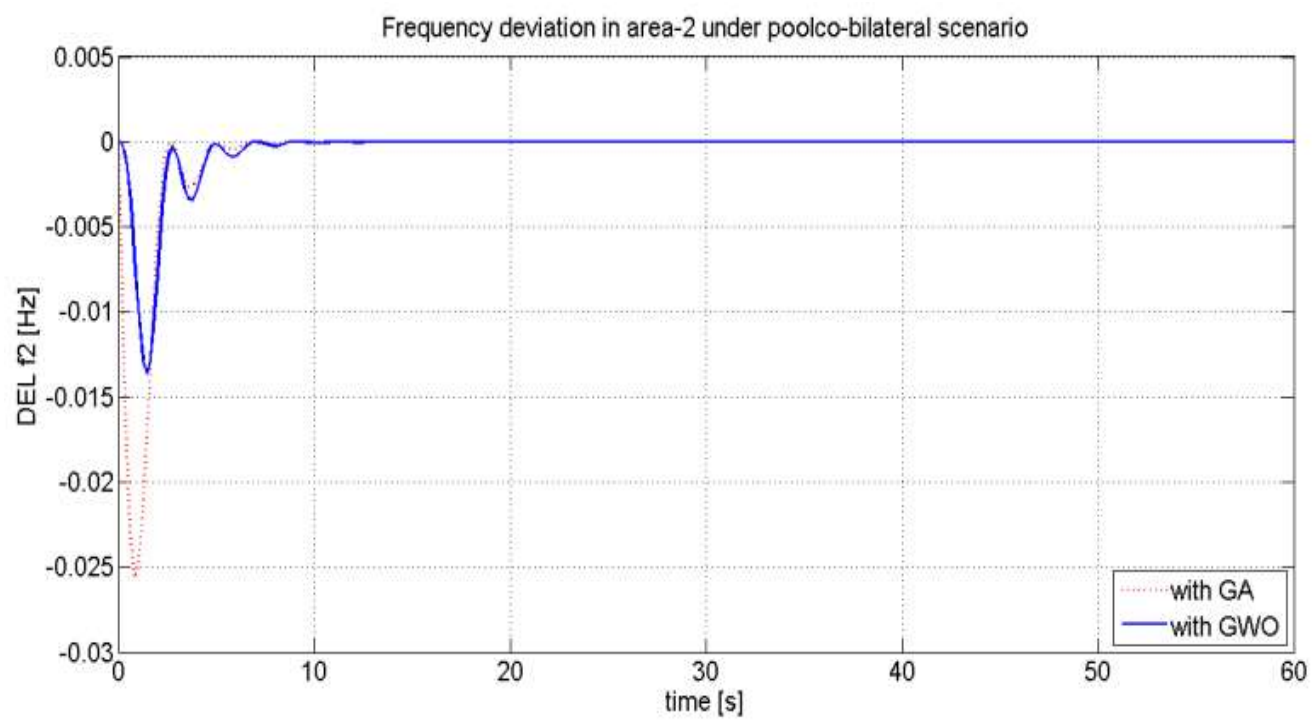

Figure 7. Frequency Deviation in area-2 under Bilateral Scenario

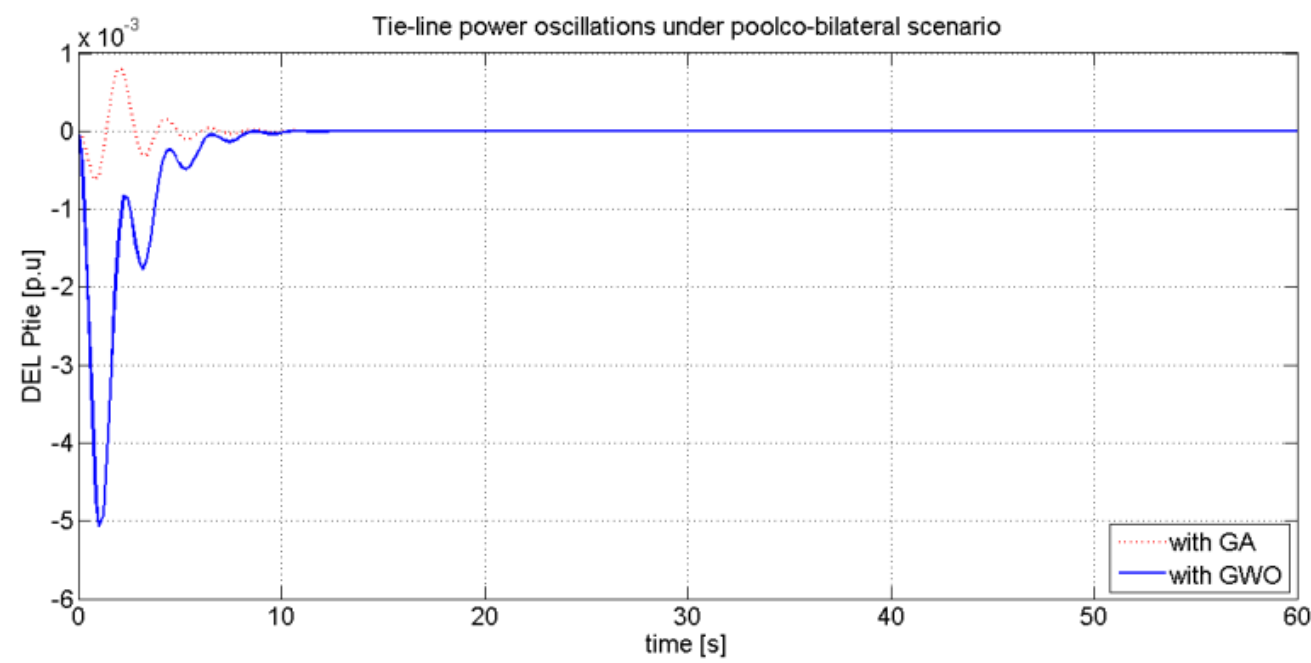

Figure 8. Tie-line Oscillations Under Bilateral Scenario

The performance comparison between GA tuned and GWO tuned controller under bilateral scenario is presented in Table 2.

\section{Table 2. Comparison of ITAE, Settling Time and Peak Overshoot Under Bilateral Scenario}

\begin{tabular}{|c|c|c|c|}
\hline \multicolumn{2}{|c|}{ Performance Index } & GA & GWO \\
\hline \multicolumn{2}{|c|}{ ITAE } & 5.673 & 5.442 \\
\hline \multirow{3}{*}{$\begin{array}{c}\text { Settling time } \\
\text { (Ts in sec) }\end{array}$} & $\Delta \mathrm{f}_{1}$ & 10.66 & 9.92 \\
\cline { 2 - 4 } & $\Delta \mathrm{f}_{2}$ & 10.28 & 10.16 \\
\cline { 2 - 4 } & $\Delta \mathrm{P}_{\text {tie }}$ & 10.06 & 9.91 \\
\hline \multirow{2}{*}{$\begin{array}{c}\text { Peak } \\
\text { overshoot }\end{array}$} & $\Delta \mathrm{f}_{1}$ & 0.026 & 0.021 \\
\cline { 2 - 4 } & $\Delta \mathrm{f}_{2}$ & 0.025 & 0.021 \\
\cline { 2 - 4 } & $\Delta \mathrm{P}_{\text {tie }}$ & 0.0014 & 0.005 \\
\hline
\end{tabular}




\subsection{Contract Violation Scenario:}

Sometimes DISCOs may not abide to contracts by demanding more power than they contracted, such an excess demand is called as uncontracted power and this is the contract violation scenario. DPM and APM under this scenario are given below (30), (31).

$$
\begin{gathered}
\mathrm{DPM}=\left[\begin{array}{cccc}
0.35 & 0.3 & 0.33 & 0.25 \\
0.15 & 0.2 & 0.17 & 0.25 \\
0.3 & 0.35 & 0.25 & 0.3 \\
0.2 & 0.15 & 0.25 & 0.2
\end{array}\right] \\
\mathrm{APM}=\left[\begin{array}{cc}
0.4 & 0.25 \\
0.1 & 0.25 \\
0.25 & 0.35 \\
0.25 & 0.15
\end{array}\right]
\end{gathered}
$$

Similarly, dynamic response of two-area power system under contract violation scenario is shown in Figure 9, Figure 10 and Figure 11.

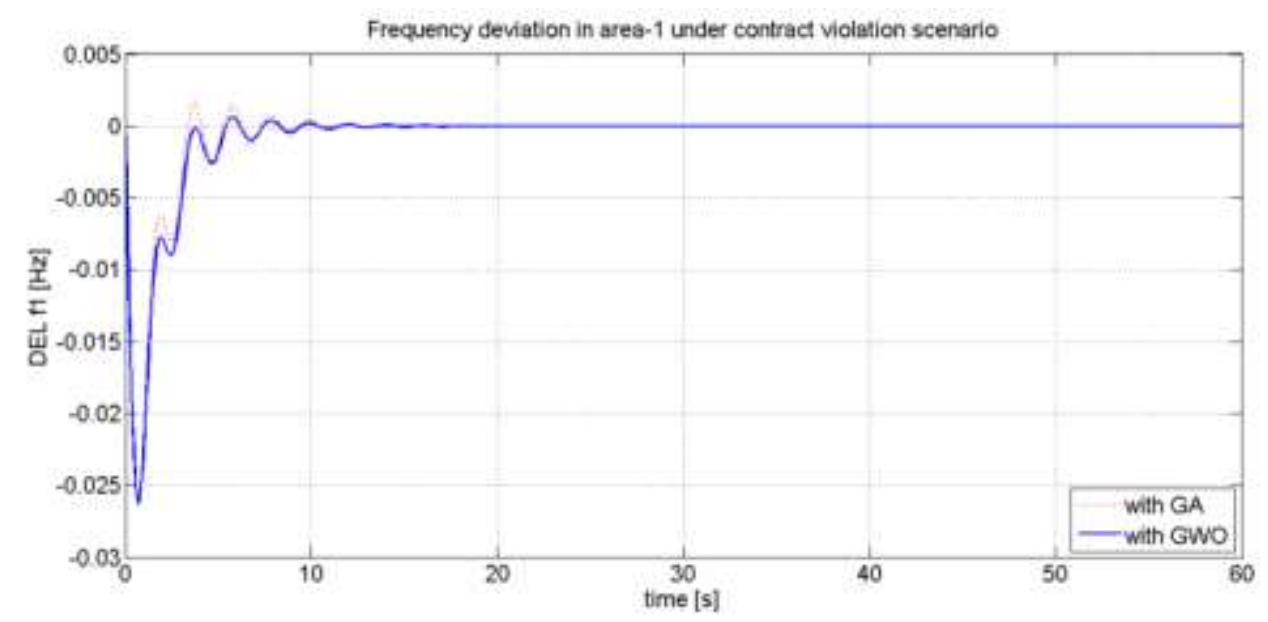

Figure 9. Frequency Deviation in Area-1 Under Contract Violation Scenario

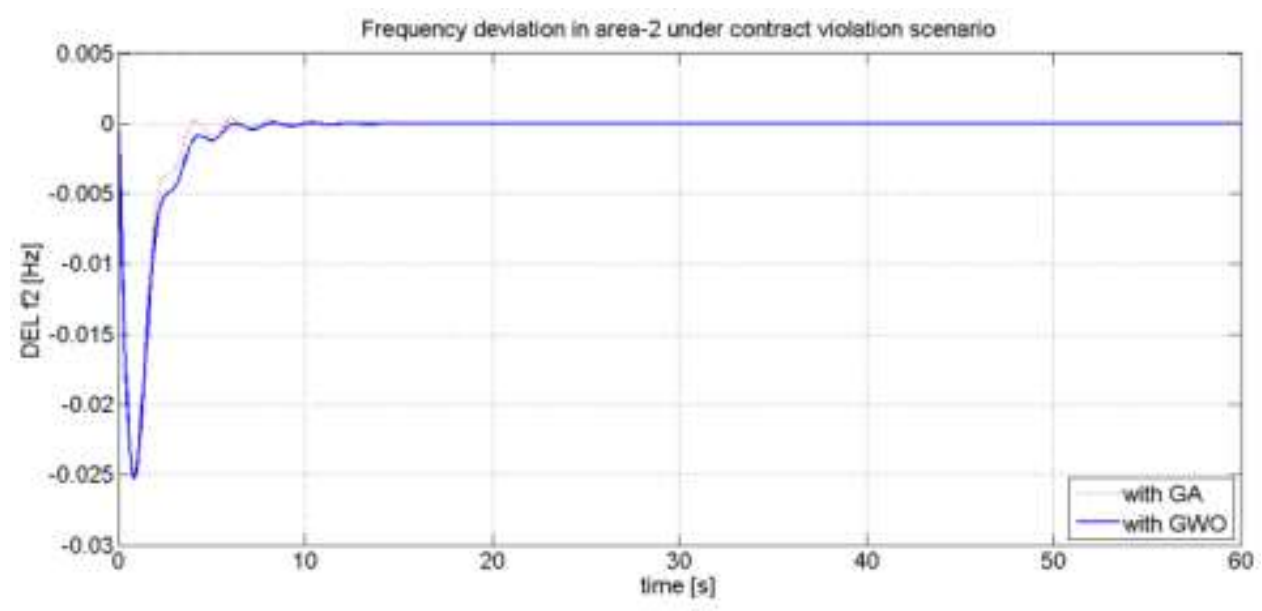

Figure 10. Frequency Deviation in Area-2 Under Contract Violation Scenario 


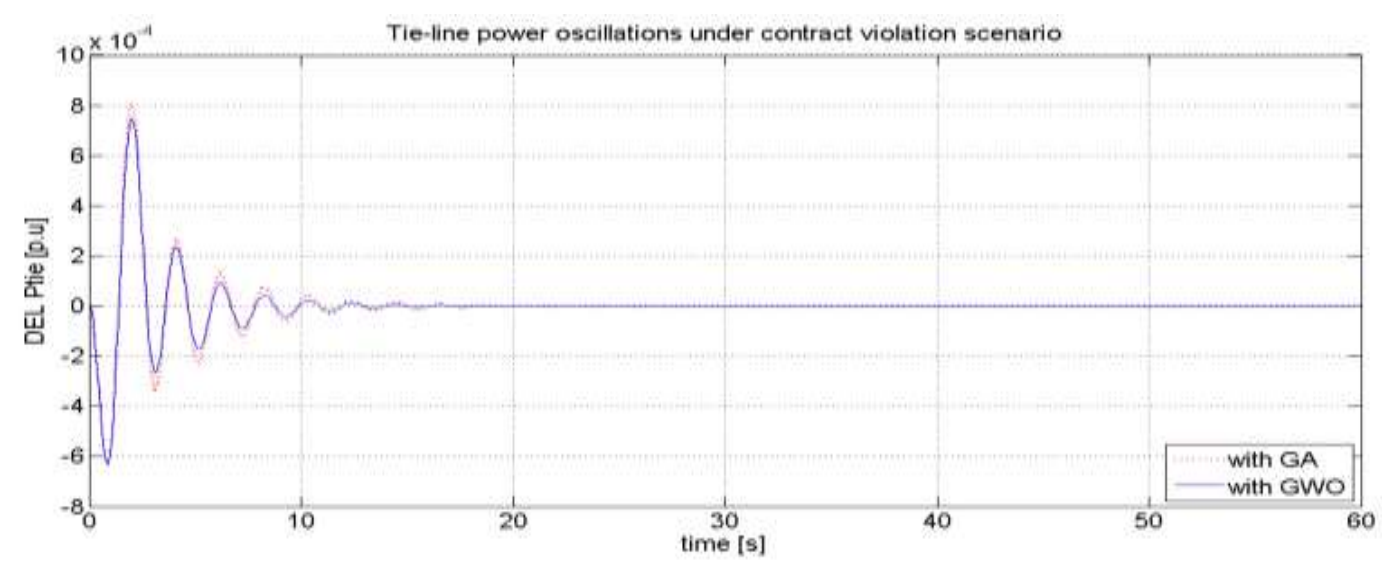

Figure 11. Tie-line Oscillation under Contract Violation Scenario

Under contract violation condition, the performance conditions are compared between GA and GWO and it is presented in Table 3.

\section{Table 3. Comparison of ITAE, Settling Time and Peak Overshoot under Contract Violation Scenario}

\begin{tabular}{|c|c|c|c|}
\hline \multicolumn{2}{|c|}{ Performance Index } & $\boldsymbol{G A}$ & $\boldsymbol{G W O}$ \\
\hline \multicolumn{2}{|c|}{ ITAE } & 4.235 & 4.015 \\
\hline \multirow{3}{*}{$\begin{array}{c}\text { Settling time } \\
\text { (Ts in sec) }\end{array}$} & $\Delta \mathrm{f}_{1}$ & 10.22 & 10.02 \\
\cline { 2 - 4 } & $\Delta \mathrm{f}_{2}$ & 10.32 & 10.12 \\
\cline { 2 - 4 } & $\Delta \mathrm{P}_{\text {tie }}$ & 9.67 & 9.51 \\
\hline \multirow{3}{*}{ Peak overshoot } & $\Delta \mathrm{f}_{1}$ & 0.028 & 0.024 \\
\cline { 2 - 4 } & $\Delta \mathrm{f}_{2}$ & 0.032 & 0.022 \\
\cline { 2 - 4 } & $\Delta \mathrm{P}_{\text {tie }}$ & 0.002 & 0.0045 \\
\hline
\end{tabular}

In above all the cases we can observe that dynamic performance is very much better in the case of Grey Wolf Optimizer tuned controllers than Genetic Algorithm tuned. Also this is compared through ITAE error criteria in all the cases and the comparison is provided in the tables and from these tables we observe the superiority of GWO algorithm.

\section{Conclusion}

In this paper to address the Load frequency control problem under deregulated conditions a new optimization algorithm named Grey Wolf Optimization(GWO) is used. The conventional PID controller is used and it is tuned by GWO. In this case Generation Rate Constraints (GRC) are also implemented. ITAE is used as error function to evaluate the performance of proposing method and this method is compared with Genetic Algorithm (GA) tuned PID controller. This work is carried out on MATLAB simulation and the results are compared. From the results analysis we infer the superiority of GWO method.

\section{Acknowledgements}

Authors wishes to acknowledge Dr. K. Subbaramaiah, Principal, YITS, Miss. K. Yamuna and Miss. K. Kranthi priya, Assistant professors, Department of EEE, YITS for great support and encouragement. 


\section{References}

[1] P. L. L. Lai, "Power System Restructuring and Deregulation Trading, Performance and Information Technology", John Wiley \& Sons, Chichester, UK, (2001).

[2] E. Rakhshani and J. Sadeh, "Practical viewpoints on load frequency control problem in a deregulated power system", Energy Conversion and Management, vol. 51, no. 6, (2010), pp. 1148-56.

[3] A. Pappachen and A. Peer Fathima, "Critical research areas on load frequency control issues in a deregulated power system: A state-of-the-art-of-review", Renewable and Sustainable Energy reviews, vol. 72, (2017), pp. 163-177.

[4] Y. Arya and N. Kumar, "Fuzzy gain scheduling controllers for automatic generation control of two-area interconnected electrical power systems", Electric Power Components Systems, vol. 44, no. 7, (2016) pp. 737-51.

[5] A. K. Pal, P. Bera and K. Chakraborty, "AGC in two-area deregulated power system using reinforced learning neural network controller", Proceedings of First International Conference on Automation, Control, Enegy and Systems, (2014) February 1-2, pp. 1-6.

[6] P. Abhijith and A. P. Fathima, "Load frequency control in deregulated power system integrated with SMES-TCPS combination using ANFIS controller", International Journal on Electrical Power and Energy Systems, vol. 82, (2016), pp. 519-534.

[7] A. Pappachen and A. P. Fathima, "Genetic algorithm based PID controller for a two-area deregulated power system along with DFIG unit", ARPN Journal of Engineering and Applied Sciences, vol. 10, no. 9, (2015), pp. 3991-3996.

[8] S. S. Dhillon, J. S. Lather and S. Marwaha, "Multi objective load frequency control using hybrid bacterial foraging and particle swarm optimized PI controller", International Journal on Electric Power and Energy Systems, vol. 79, (2016), pp. 196-209.

[9] H. Shayeghi, H. A. Shayanfar and A. Jalili, "LFC design of a deregulated power system with TCPS using PSO", International Journal of Electrical, Computer, Energitic and Electronics Communication Engineering, vol. 3, no. 4, (2009), pp. 691-699.

[10] G. T. Chandra Sekhar, R. Kumar Sahu, A. K. Baliarsingh and S. Panda, "Load frequency control of power system under deregulated environment using optimal firefly algorithm", International Journal on Electrical Power and Energy Systems, vol. 74, (2016), pp. 195-211.

[11] C. K. Shiva and V. Mukherjee, "Automatic generation control of multi-unit multi-area deregulated power system using a novel quasi-oppositional harmony search algorithm", IET Transactions on Generation Transmission and Distribution, vol. 9, no. 15, (2015), pp. 2398-2408.

[12] A. Yuva Kishore and G. Ravindra, "Robust controller for hydroplants to mitigate frequency deviations with wind power penetration in the grid", International Journal of Adv. Research in Electical, Electronics and Instrumentation Engineering, vol. 6, no. 5, (2017), pp. 3568-3577.

[13] Y. Mi, Y. Fu, D. D. Li, C. S. Wang, P. C. Loh and P. Wang, "The sliding mode load frequency control for hybrid power system based on disturbance observer," International Journal on Electrical Power and Energy Systems, vol. 74, (2016), pp. 446-452.

[14] M. Shiroei, A. M. Ranjbar and T. Amraee, "A functional model predictive control approach for power system load frequency control considering generation rate constraint", International Transactions on Electrical Energy Systems, vol. 23, no. 2, (2013), pp. 214-229.

[15] K. Bhattacharya, M. Bollen and J. Daalder, "Operation of Restructured Power System", Norwell, MA, USA: Kluwer, (2001).

[16] V. Donde, M. A. Pai and I. A. Hiskens, "Simulation and optimization in an AGC system after deregulation", IEEE Transaction on Power Systems, vol. 16, no. 3, (2001), pp. 481-489.

[17] S. Mirjalili, S. M. Miralil and A. Lewis, "Grey Wolf optimizer", Advances in Engineering Software, vol. 69, (2014), pp.46-61.

\section{Authors}

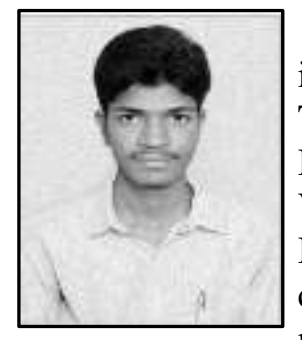

A. Yuva Kishore, is currently working as Assistant professor in the Department of EEE, Annamacharya Institute of Technology and Sciences (AITS), Tirupathi, Andhra Pradesh, India. He pursued his post-graduation M.Tech from Sree Vidyanikethan Engineering College(Autonomous), Tirupathi, India in 2017 and did his Graduation B.Tech from JNTUA college of Engineering, Pulivendula in 2014. He Published 5 national/international journal/conference papers. His areas of interest include Power system Dynamics, Deregulated power systems and Renewable Energy Sources. 

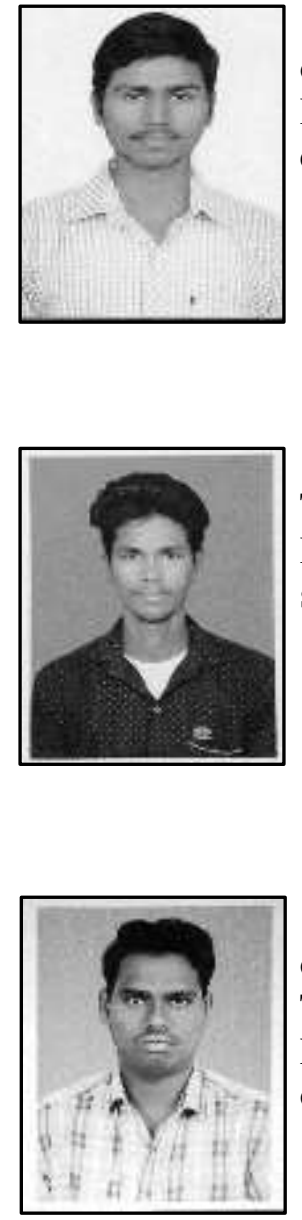

P.V. Naresh Babu, is a graduate student in Yoganada Institute of Technology and Sciences (YITS), Tirupathi, Andhra Pradesh, India. His area of interest includes Power systems operation and control, Deregulated power systems.

J. Chinnaraj, is a graduate student in Yoganada Institute of Technology and Sciences (YITS), Tirupathi, Andhra Pradesh, India. His area of interest includes Artificial intelligence, Power system optimization.

E. Murali Raghava, is an industrial trainer under the project of APSSDC Siemens in Sree Vidyanikethan Engineering College, Tirupathi, Andhra Pradesh, India. His area of interest includes Power electronic converters, Power systems control and operation. 